\title{
Isolation of Antibiotic Producing Bacteria from Lake Soil
}

\author{
Nayudu Teja, Ooha Deepika Gummadi* and Boppudi Pujitha \\ Department of Pharmaceutics, V.V. Institute of Pharmaceutical Sciences, Gudlavalleru, \\ Krishna District, Andhra Pradesh, India \\ *Corresponding Author: Ooha Deepika Gummadi, Department of Pharmaceutics, \\ V.V. Institute of Pharmaceutical Sciences, Gudlavalleru, Krishna District, Andhra \\ Pradesh, India.
}

Received: September 30, 2020

Published: October 16, 2020

(C) All rights are reserved by Ooha Deepika

Gummadi., et al.

\begin{abstract}
Microorganisms are present in almost all places on the earth. They are very important in the maintenance of life on the earth. Due the difference in the activities of different microbes, they influence life in different ways.
\end{abstract}

Keywords: Microorganism; Algae; Protozoa

\section{Introduction}

Micro-organisms and their activities are vitally important to virtually all processes on Earth. Micro-organisms matter because they affect every aspect of our lives - they are in us, on us and around us. Microorganisms include bacteria, fungi, protozoa, algae and viruses. Microorganisms may be single-celled like bacteria, some algae and protozoa, or multicellular, such as algae and fungi. Microbes play key roles in nutrient cycling, biodegradation/biodeterioration, climate change, food spoilage, the cause and control of disease, and biotechnology [1].

\section{Need of isolation of microorganisms}

Microorganisms occur in natural environment like soil. They are mixed with several other forms of life. Many microbes are pathogenic. They cause a number of diseases with a variety of symptoms, depending on how they interact with the patient. The isolation and growth of suspected microbe in pure culture is essential for the identification and control the infectious agent.

The primary culture from natural source will normally be a mixed culture containing microbes of different kinds. But in laboratory, the various species may be isolated from one another. A culture which contains just one species of microorganism is called a pure culture. The process of obtaining a pure culture by separating one species of microbe from a mixture of other species is known as isolation of the organisms.

\section{Methods of isolation}

There are special techniques employed to obtain pure cultures of microorganisms. In few cases it is possible to secure pure culture by direct isolation or direct transfer. This can be done only in those situations in which pure culture occurs naturally. Kinds of specimens taken for culturing will depend on the nature and habitat of microbes.

Different pathogens can be isolated from body tissues and fluids such as blood, urine, sputum, pus, faces, spinal fluid, bile, pleural fluids, stomach fluids etc. In the blood stream of a patient suffering with typhoid fever, the bacteria Salmonella typhosa may be present.

A pure culture of this bacterium may be obtained by drawing blood sample using sterilized hypodermic syringe and treating the blood with anticoagulant such as heparin and potassium oxalate. The presence of the anticoagulant prevents the pathogenic microbe from entrapping in fibrin clot. The sample of the blood may be inoculated into a suitable Medium.

A pure culture of this bacterium may be obtained by drawing blood sample using a sterilized hypodermic syringe and treating the blood with anticoagulant such as heparin and potassium oxalate. The presence of the anticoagulant prevents the pathogenic microbe from entrapping in fibrin clot. The sample of the blood may be inoculated into a suitable Medium. 
Following isolation methods are employed to isolate microbes from mixed cultures:

- Streaking

- Plating

- Dilution

- Enriched procedure, and

- Single cell technique.

\section{Streaking}

This is most widely used method of isolation. The technique consists of pouring a suitable sterile medium into sterile petriplate and allowing the medium to solidify. By means of a sterile loop or straight needle or a sterile bent glass-rod a small amount of growth preferably from a broth culture or bacterial suspension is streaked back and forth across the surface of agar until about one third of the diameter of the plate has been covered.

The needle is then flamed and streaking in done at right angles to and across the first streak. This serves to drag bacteria out in a long line from the initial streak. When this streaking is completed the needle is again flamed and streaking is done at right angles to the second streak and parallel to the first.

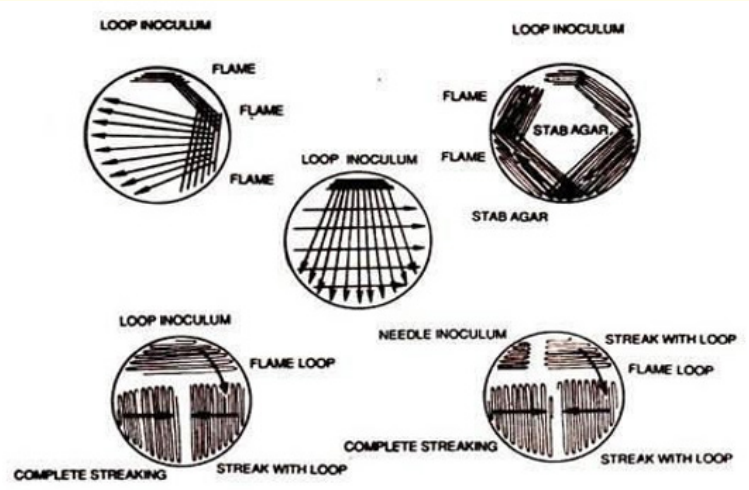

Figure 1: Streaking.

Plating

It includes diluting of a mixture of microorganisms until only a few hundred bacteria are left in each milliliter of the suspension. A very small amount of the dilution is then placed in a sterile petriplate by means of a sterile loop or pipette. The melted agar medium is cooled to about $45^{\circ} \mathrm{C}$ and is poured into plate. The microorganism and agar are well mixed. When the agar is solidified the individual bacterium will be held in place and will grow to a visible colony.

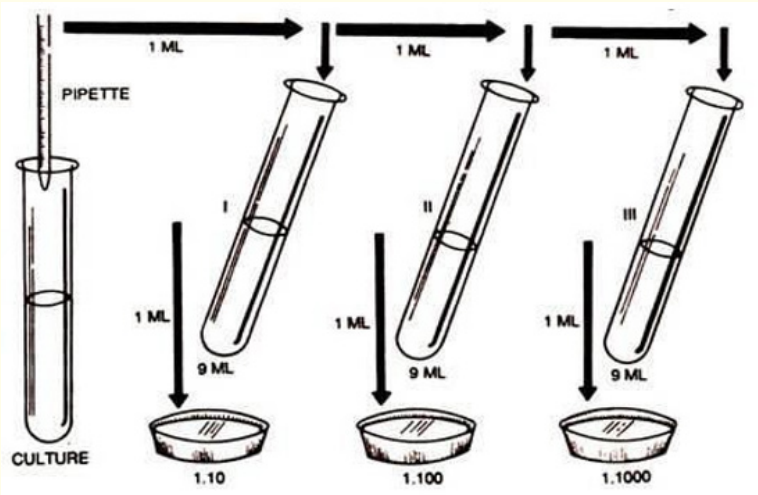

Figure 2: Serial dilution.

\section{Dilution}

This method is used for the microorganisms which cannot be easily isolated by streaking or plating method. Sometimes when several organisms are present in a mixture, with one organism predominating, the predominating form may be isolated by this method. For example, when raw milk is allowed to sour at room temperature it will, at the time of curding, have a mixture of microorganisms with high percentage of Streptococcus lactis.

If $1 \mathrm{ml}$ of the sour milk is taken into a tube containing $9 \mathrm{ml}$. of sterile milk (in which no organisms are present) then $1 \mathrm{ml}$. of this mixture is transferred with a sterile pipette into a second tube of sterile milk and the procedure is repeated i.e. from second to third tube, third to fourth tube until a series of about 10 tubes are inoculated. By this serial dilution, the chances are that a pure culture of S. lactis will be obtained.

Enrichment procedure

This procedure involves the use of media and conditions of cultivation which favour the growth of the desired species. For example, when a man suffers with typhoid, the intestinal discharge possess small number of Salmonella typosa when compared with $E$. coli and other forms.

It is almost impossible to isolate the typhoid organisms because they represent only a fraction of a per cent of the total microorganism's present. The media are therefore derived, which allow the rapid growth of the desired organisms, at the same time inhibiting the growth of other microorganisms. 


\section{Single technique}

This is one of the most ideal and difficult method of securing pure culture. In this method a suspension of the pure culture is placed on the under-side of a sterile cover-glass mounted over a moist chamber on the stage of the microscope.

While looking through the microscope, a single cell is removed with the help of sterile micropipette and transferred to a small drop of sterile medium on a sterile cover-glass and is mounted on a sterile hanging drop slide, which is then incubated at suitable temperature. If the single cell germinates in this drop, few cells are transferred into a tube containing sterile culture medium which is placed in the incubator to obtain pure culture originated from single cell.

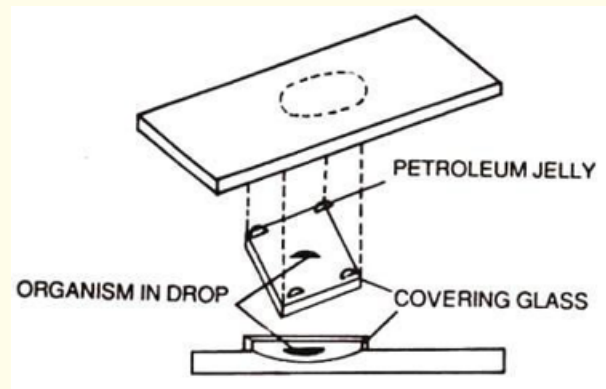

Figure 3: Single technique.

\section{Other methods}

The isolation of anaerobic microorganisms is very difficult. There are certain special techniques by which these organisms are isolated.

\section{Importance of crowded plate techniques}

The crowded plate technique is fairly simple indeed, the simplest method to find antibiotic-producing microorganisms in soil samples. It's also fairly rapid, taking only a couple of days to produce results. Introducing "test organisms" can help to determine whether a specific kind of microorganism (e.g., a disease-causing germ) is susceptible to the antibiotic compound. If it does indeed prove useful for this purpose, the compound can be isolated for further study.

\section{Materials and Methods}

Collection of soil sample: From local area of Vijayawada 10 samples of Krishna river soil were collected aseptically from various locations. The collected samples were transferred to the labo- ratory, where entire work is carried. The composite sample was preserved aseptically for the further work.

Serial dilution of soil: A series of 5 test tubes containing sterile water each $9 \mathrm{ml}$ were taken. To the first test tube $1 \mathrm{gm}$ of soil composite sample was added and with the help of vortex mixer, an uniform suspension was obtained. From the test tube one $1 \mathrm{ml}$ of suspension is transferred to $2^{\text {nd }}$ test tube and labelled as $10^{-2} \mathrm{di}^{-}$ lution. In similar manner the dilution up to $10^{-5}$ were made using serial dilution. From these test tubes labelled $10^{-3}$ to $10^{-5}$ were selected and subjected for spread plate technique.

Isolation of colonies: $1 \mathrm{ml}$ of aliquot from selected dilutions were transferred to nutrient agar plates individually with the help of sterile L- spreader. So prepared plates were incubated at $30^{\circ} \mathrm{C}$ for 2 to 7 days. The plates were observed for the growth of organisms.

Crowded plate method: For screening of antibiotic producing organisms, the simplest technique is "crowded plate" procedure. This technique is used where one is interested only in finding microorganisms that produces an antibiotic irrespective of its action against any specific organism. Hence, the sample is diluted only to such an extent that agar plates prepared from these dilutions will be crowded with individual colonies on agar surface, i.e. 300 to 400 colonies or more. Colonies producing antimicrobial activity are indicated by clear zone of growth inhibition surrounding the colony. Such colony is later on sub cultured, purified, and afterwards microbial inhibition spectrum is tested against selective microorganisms.

The incubated plates were observed for the colonies with zone of inhibition. The colonies with zone of inhibition were isolated and subjected for purification by multiple streak technique.

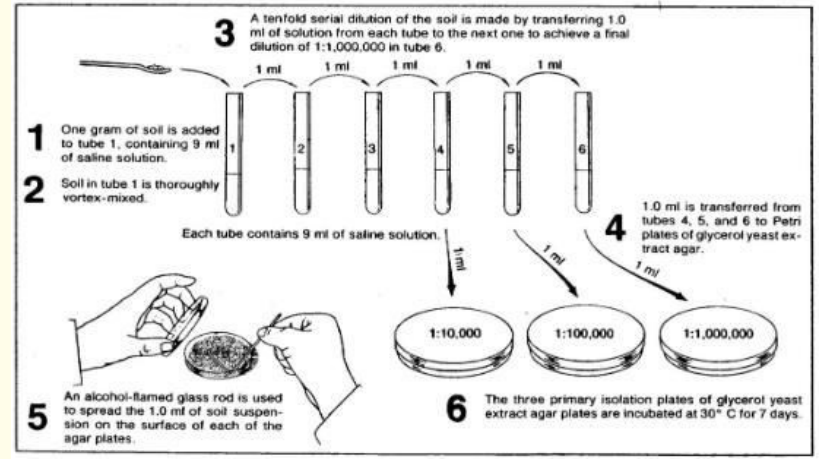

Figure 4: Demonstration for serial dilution and isolation of colonies. 
Thus, isolated colonies were subjected to morphological and biochemical screening.

\section{Morphological screening of isolated colonies}

For isolated colonies morphological characterization like gram staining, endospore staining and motility test were performed.

\section{Gram staining}

This technique is used to distinguish Gram negative and Gram positive bacteria. Gram negative bacteria contain more amount of lipid than that of gram positive. During the staining process, alcohol treatment extracts the lipid, which increases the permeability of the cell wall. Thus, crystal violet-Iodine complex can be extracted and is decolorized.

After straining looks violet as it retained the crystal violet dye. Whereas the gram (-) ve bacterial shows pink colour as it had retained safranin.

Procedure: On to clean glass slide a loop full of $24 \mathrm{hrs}$ culture with the help of inoculating needle is transferred and a smear is prepared. The smear was dried and 1- 2 drops of crystal violet or a primary dye added and allowed to stand for 1 - 2 minutes. The smear was flooded by keeping it under gently running tap water without disturbing the prepared smear. Immediately 1 - 2 drops of gram iodine solution added. Allow to stand for $1 \mathrm{~min}$. and then the smear was washed by placing it under running tap water. The slide was further washed with decolorizing agent i.e. 35\% alcoholic solution. 3 drops of safranin or tertiary dye which may be attracted to the cells which loses coloration after adding discoloring agent is added. Allow to stand for 2 minutes and flood it by placing it under gently running tap water. The smear is dried and mounted under microscope under high power lens.

\section{Endospore staining}

Because of its chemical composition the spore is resistant to effects of heat, freezing, radiation and other chemical agents. When favorable conditions prevail, the spores will germinate and become metabolically active. Spores resist staining but once they are stained, they resist decolourization and counter staining. Due to heat treatment, pores of spore become wider and facilitate the staining with strong basic stains. Employment of decolourizer selectively decolorizes cytoplasm and not the spores.

Procedure: On to clean glass slide smear of organism is made and subjected to air drying followed by heat fixation. The slide is placed on rim of beaker of boiling water bath such that smear side faces upwards. When large drops of water condense on lower of the slide, the smear was covered with $5 \%$ aqueous malachite green solution (primary stain) the stain is allowed to react for 2 - 3 minutes the slide was removed from water bath and allowed to cool and washed under tap water (decolorizing agent). The smear was treated with $0.5 \%$ safranin (counter stain) for 30 seconds and again wash with water, air dry and examine under oil immersion objective which has green color.

\section{Motility testing}

Wet mount and hanging drop techniques are commonly used for direct examination of living microorganisms. This hanging drop method has the following advantages:

- It is easy to study motility of bacteria and is less time consuming

- Hanging drop is surrounded by air space hence, capacity of aeration is increased.

- It is also used for observation of size, shape of microorganisms in living state.

Procedure: A clean and sterile cavity slide was taken to that by using a needle, a thin layer of petroleum jelly on periphery of cavity slide was applied. On a clean covers slip petroleum jelly was applied on four corners of the cover slip using needle. A loop full of culture was transferred on the center of cover slip. The cavity slide was inverted over the cover slip containing culture drop. The slide was mounted on microscope stage carefully focusing the edge of the drop so that it appears across the center of the field. By using high power objective and adjusting the amount of light intensity to obtain sharp view.

\section{Biochemical characterization}

The following biochemical test were performed on isolated colonies.

\section{Indole production test}

This test is performed to determine the ability of microorganism to degrade the amino acid tryptophan by producing enzyme tryptophanase.

Medium: SIM broth

Peptone: 30 gm.

Beef extract: $5 \mathrm{gm}$. 
Sodium thiosulfate: 0.2 gm Ferrous ammonium sulfate $25 \mathrm{gm}$ Distilled water $1000 \mathrm{ml}$.

Procedure: Prepare SIM broth medium and inoculate with test microorganisms. Keep one tube as uninoculated comparative control. Incubate all the inoculated tubes for $24-48 \mathrm{hrs}$ at $37^{\circ} \mathrm{C}$. After incubation, add $1 \mathrm{ml}$ of kovac's reagent to each tube including control.

\section{Voges-Proskauer test}

This test is performed to differentiate enteric microorganisms such as Escherichia coli and Enterobacter aerogenes by Voges Proskauer test.

Medium: MR-VP broth.

Peptone: $7 \mathrm{gm}$.

Glucose: $5 \mathrm{gm}$.

Dipotassium phosphate: 5 gm Distilled water $1000 \mathrm{ml}$.

Procedure: Prepare MR-VP broth and sterilize at $121^{\circ} \mathrm{C}$ for 15 minutes cool all the test tubes at room temperature and inoculate test microorganisms. Keep one test tube as a control. Incubate all the inoculated tubes at $37^{\circ} \mathrm{C}$ for $24-48 \mathrm{hrs}$. After incubation, add 8-10 drops of Barritt's reagent A. Shake the cultures add 8 - 10 drops Barritt's reagent Band again shake the cultures.

\section{Methyl red test}

This test determines the ability of microorganism to oxidize glucose and produce acid.

Medium: MR-VP broth.

Procedure: Prepare MR-VP broth and sterilize by autoclaving at $121^{\circ} \mathrm{C}$ for 15 minutes. Cool at room temperature and inoculate the tubes with test organism. Keep one tube as inoculated control. Incubate all the inoculated tubes for $24-48 \mathrm{hrs}$ at $37^{\circ} \mathrm{C}$. After incubation, add 4 - 5 drops of methyl red indicator to all test tubes.

\section{Citrate utilization test}

This is to differentiate enteric microorganisms by the presence of citrate which act as sole carbon source.

Medium: Simmons citrate broth.

Ammonium dihydrogen phosphate: $1 \mathrm{gm}$.

Dipotassium phosphate: $1 \mathrm{gm}$.

Sodium chloride: $5 \mathrm{gm}$.

Sodium citrate: $2 \mathrm{gm}$.
Magnesium sulphate: $0.2 \mathrm{gm}$.

Bromothymol blue: $80 \mathrm{mg}$.

Distilled water: $1000 \mathrm{ml}$.

Procedure: Prepare simmons citrate broth and sterilize by autoclaving at $121^{\circ} \mathrm{C}$ for 15 minutes. Cool all test tubes and inoculate the test microorganisms. Keep one tube as a control. Incubate all the test tubes for 24 to $48 \mathrm{hrs}$ at $37^{\circ} \mathrm{C}$. The shift in $\mathrm{pH}$ turns the bromothymol blue indicator in the medium from green to blue.

\section{Urease test}

This test is to determine the ability of microorganisms to degrade urea by producing enzyme urease.

Medium: Urease broth.

Urea: 20 gm.

Sodium chloride: 5.0 gm.

Mono Potassium phosphate: $2.0 \mathrm{gm}$.

Peptone: $1.0 \mathrm{gm}$.

Dextrose: $1.0 \mathrm{gm}$.

Phenol red: 0.012 gm.

Distilled water: $1000 \mathrm{ml}$.

Procedure: Prepare urease broth medium and label with the test microorganisms. Inoculate the urea broth medium with medium with the test microorganisms. Incubate all the test tubes for 24 to $48 \mathrm{hrs}$ at $37^{\circ} \mathrm{C}$. Observed for colour change from orange yellow color to bright pink.

\section{Nitrate reduction test}

This test is performed to determine the ability of microorganism to produce nitrate reductase.

Medium: Trypticase nitrate broth Trypticase (animal peptone): $20 \mathrm{gm}$.

Disodium phosphate: $2 \mathrm{gm}$.

Dextrose: $1 \mathrm{gm}$.

Potassium nitrate: $1 \mathrm{gm}$.

Distilled water: $1000 \mathrm{ml}$.

Procedure: Prepare a nitrate broth medium and label with the name of test microorganisms. Using sterile technique, inoculate test microorganisms by loop inoculation method. Incubate all test tubes for 24 to $48 \mathrm{hrs}$ at $37^{\circ} \mathrm{C}$. After incubation, add 4 - 5 drops of reagent to all nitrate broth tubes. Colour change to red indicates positive. 


\section{Oxidase test}

Medium: Trypticase soy.

Agar trypticase: $20 \mathrm{gm}$.

Dipotassium phosphate: $20 \mathrm{gm}$.

Glucose: $1 \mathrm{gm}$.

Bromothymol blue: $0.075 \mathrm{gm}$.

Agar: 1 gm.

Distilled water: $1000 \mathrm{ml}$.

Procedure: Prepare the trypticase soy agar plates and label with the name of test microorganism. Using sterile technique, make a single line streak inoculation of test microorganism on the surface of agar plate. Incubate the plate for 24 - 48 hrs at 37으. After incubation, add 2 - 3 drops of tetramethyl-p-phenylenediamine dihydrochloride on the surface of the growth of test microorganism.

\section{Catalase test}

This test is performed to determine the ability of microorganism to produce catalase enzyme.

Medium: Trypticase soy agar.

Procedure: Prepare trypticase soy agar plates and label with the name of test microorganisms. Using sterile technique, make a single line streak inoculation of test microorganisms. Incubate the plates for $24-48 \mathrm{hrs}$ at $37^{\circ} \mathrm{C}$. After incubation, add 3 - 4 drops of hydrogen peroxide on the growth of test microorganisms.

\section{Gelatin hydrolysis test}

Medium: Nutrient gelatin deep tubes peptone: $5 \mathrm{gm}$.

Beef extract: 3 gm.

Gelatin: 120 gm

Distilled water: $1000 \mathrm{ml}$

Procedure: Prepare nutrient gelatin deep tubes and label with the name of the bacterial test culture. Using an inoculating wire loop, make a stab inoculation from test microorganism into deep tube of nutrient gelatin. Uninoculated deep tubes should be used as a control. Incubate all the inoculated tubes for 24 to $48 \mathrm{hrs}$ at $37^{\circ} \mathrm{C}$. After incubation, place the tubes in a refrigerator at 4 for 15 minutes.

\section{Starch hydrolysis}

Medium: Starch agar.
Peptone: $5 \mathrm{gm}$.

Beef extract: $3 \mathrm{gm}$.

Starch (soluble): $20 \mathrm{gm}$.

Agar: 20 gm.

Distilled water: $1000 \mathrm{ml}$.

Procedure: Prepare the starch agar plates and label with the name of microorganism to be inoculated. Using sterile technique, make a single streak inoculation of microorganism into the centre of starch plate. Incubate the plates at $37^{\circ} \mathrm{C}$ for $48 \mathrm{hrs}$. Flood the starch agar plates with Gram's iodine solution after the growth of test microorganisms. Pour the excess iodine solution from the plate.

\section{Carbohydrate test}

Medium: Peptone water containing sugar such as lactose, mannitol, sucrose, dextrose, fructose.

Peptone: $10 \mathrm{gm}$.

Sodium chloride: $5 \mathrm{gm}$.

Distilled water: $1000 \mathrm{ml}$.

Procedure: Prepare 10\% carbohydrate solution (glucose, lactose, mannitol, sucrose, dextrose) in water and sterilize by membrane filtration. Add $10 \mathrm{ml}$ of carbohydrate solution to each $100 \mathrm{ml}$ sterile peptone water to make final concentration of $1 \%$ sugar in the medium. Add specific quantity of medium containing different test tubes. A Small Durham tube filled with medium and containing no air bubbled incubated inverted position in each culture tube to detect the gas. Using sterile technique, inoculate each test microorganism in to its approximately labeled medium by loop inoculation. Incubate all the test tubes at $35^{\circ} \mathrm{C}$ to $37^{\circ} \mathrm{C}$ for 24 to $48 \mathrm{hrs}$.

\section{Screening for antimicrobial activity}

Primary screening for evaluating the antimicrobial potential of the isolated cultures was performed by perpendicular streak method. Isolates were screened for antagonism studies by inoculating a single streak of the pure producer organism in the middle of the assay media plate. The plates were incubated for 4 days at $28^{\circ} \mathrm{C}$ and subsequently seeded with "test" organism by a single streak at a $90^{\circ}$ angle to the streak of the "producer strain" and finally the plates were incubated for $1-2$ days at $28^{\circ} \mathrm{C}$. The microbial interactions were analyzed by determining the distance of inhibition measured in mm. 


\section{Results and Discussion}

Isolation of colonies

By performing crowded plate technique five colonies with zone of inhibition were isolated. These colonies were labeled as colony 1 to 5 .

\section{Morphological characterization}

The five isolated colonies were subjected to morphological characterization. Like their colony shape, colony colour, staining techniques and motility. The observations are recorded in table 1.

All the colonies were found to be bacterial colonies. Out of five isolated colonies four are gram positive cocci, and one colony i.e. colony 3 found to be gram positive rod shape organism.

\section{Biochemical characterization}

The isolated colonies were further subjected to biochemical testing. Biochemical tests are the tests used for the identification of bacteria species based on the differences in the biochemical activities of different bacteria. These differences in carbohydrate metabolism, protein metabolism, fat metabolism, production of certain enzymes, ability to utilize a particular compound, etc. help them to be identified by the biochemical tests. The observation of biochemical characterization was compiled in table 2 and 3 .

By the observation of morphological and biochemical characterization and comparing to standard literature the organisms were found to belong to Actinobacteria.

\section{Screening for antimicrobial activity}

Primary screening is carried out by using Escherichia coli, Pseudomonas aeruginosa, Staphylococcus aureus, Bacillus subtilis and Yeast by Isolates were screened for antagonism studies by inoculating a single streak of the pure producer organism in the middle of the assay media plate. The plates were incubated for 4 days at $28^{\circ} \mathrm{C}$ and subsequently seeded with "test" organism by a single streak at a $90^{\circ}$ angle to the streak of the "producer strain" and finally the plates were incubated for $1-2$ days at $28^{\circ} \mathrm{C}$. the results are presented in table 4 .

From the observation it is clear that colony 3 exhibited antimicrobial properties to words both bacteria and fungi. Colony 4 do not possess antibiotic release capability and remaining 3 colonies i.e. colony 1, 2 and 5 limited antibacterial properties.

\begin{tabular}{|l|c|c|c|c|c|c|}
\hline \multirow{2}{*}{$\begin{array}{l}\text { Name of } \\
\text { colony }\end{array}$} & Colour of colony & Nature of colony & Gram Staining & Shape & Endospore & \multirow{2}{*}{ Motility } \\
\cline { 2 - 7 } Colony 1 & White & Circular, flat and smooth & Gram positive & Cocci & Non sporulating & Non motile \\
\hline Colony 2 & Red & Rough, irregular and raised & Gram positive & Cocci & Non sporulating & Non motile \\
\hline Colony 3 & Yellowish orange & Irregular, convex and lobate & Gram positive & Rod & Non sporulating & Non motile \\
\hline Colony 4 & White & Circular large colony, raised undulate & Gram positive & Cocci & Sporulating & Non motile \\
\hline Colony 5 & White & Punctiform, flat and entire & Gram positive & Cocci & Non sporulating & Non motile \\
\hline
\end{tabular}

Table 1: Morphological characterization.

\begin{tabular}{|l|c|c|c|c|c|}
\hline Biochemical Test & Colony $\mathbf{1}$ & Colony $\mathbf{2}$ & Colony $\mathbf{3}$ & Colony $\mathbf{4}$ & Colony $\mathbf{5}$ \\
\hline Catalase test & $(+) \mathrm{ve}$ & $(+) \mathrm{ve}$ & $(+) \mathrm{ve}$ & $(+) \mathrm{ve}$ & $(+) \mathrm{ve}$ \\
\hline Oxidase test & $(+) \mathrm{ve}$ & $(+) \mathrm{ve}$ & $(-) \mathrm{ve}$ & $(-) \mathrm{ve}$ & $(+) \mathrm{ve}$ \\
\hline Nitrate reduction test & $(+) \mathrm{ve}$ & $(+) \mathrm{ve}$ & $(-) \mathrm{ve}$ & $(+) \mathrm{ve}$ & $(+) \mathrm{ve}$ \\
\hline Gelatin hydrolysis test & $(-) \mathrm{ve}$ & $(+) \mathrm{ve}$ & $(+) \mathrm{ve}$ & $(+) \mathrm{ve}$ & $(+) \mathrm{ve}$ \\
\hline Casein Hydrolysis & $(+) \mathrm{ve}$ & $(+) \mathrm{ve}$ & $(+) \mathrm{ve}$ & $(+) \mathrm{ve}$ & $(+) \mathrm{ve}$ \\
\hline Urease test & $(-) \mathrm{ve}$ & $(-) \mathrm{ve}$ & $(+) \mathrm{ve}$ & $(-) \mathrm{ve}$ & $(+) \mathrm{ve}$ \\
\hline Indole test & $(+) \mathrm{ve}$ & $(-) \mathrm{ve}$ & $(-) \mathrm{ve}$ & $(-) \mathrm{ve}$ & $(+) \mathrm{ve}$ \\
\hline Methyl Red test & $(+) \mathrm{ve}$ & $(-) \mathrm{ve}$ & $(+) \mathrm{ve}$ & $(-) \mathrm{ve}$ & $(+) \mathrm{ve}$ \\
\hline Voges Proskauer test & $(-) \mathrm{ve}$ & $(-) \mathrm{ve}$ & $(-) \mathrm{ve}$ & $(+) \mathrm{ve}$ & $(-) \mathrm{ve}$ \\
\hline Citrate utilization test & $(-) \mathrm{ve}$ & $(-) \mathrm{ve}$ & $(+) \mathrm{ve}$ & $(-) \mathrm{ve}$ & $(+) \mathrm{ve}$ \\
\hline Starch Hydrolysis test & $(+) \mathrm{ve}$ & $(-) \mathrm{ve}$ & $(-) \mathrm{ve}$ & $(+) \mathrm{ve}$ & $(+) \mathrm{ve}$ \\
\hline
\end{tabular}

Table 2: Biochemical characterization. 


\begin{tabular}{|l|c|c|c|c|c|}
\hline Carbohydrate & Colony 1 & Colony 2 & Colony 3 & Colony 4 & Colony 5 \\
\hline Lactose & G\&A & G\&A & G\&A & - & G\&A \\
\hline Mannitol & G\&A & G\&A & G\&A & G\&A & G \\
\hline Sucrose & G\&A & G\&A & G & G & G\&A \\
\hline Dextrose & G\&A & G & G & G & G\&A \\
\hline Fructose & G & G & G & G & G \\
\hline
\end{tabular}

Table 3: Carbohydrate test.

$\mathrm{G}=\mathrm{Gas}$ produced; $\mathrm{G} \& \mathrm{~A}=\mathrm{Gas}$ and Acid Production .

\begin{tabular}{|l|c|c|c|c|c|}
\hline Test organism & \multirow{2}{*}{ Escherichia coli } & $\begin{array}{c}\text { Pseudomonas } \\
\text { aeruginosa }\end{array}$ & $\begin{array}{c}\text { Staphylococcus } \\
\text { aureus }\end{array}$ & Bacillus subtilis & Yeast \\
\hline Colony & No Inhibition & Inhibited & No Inhibition & Inhibited & No Inhibition \\
\hline Colony 2 & Strong Inhibition & Strong Inhibition & Strong Inhibition & Moderate Inhibition & No Inhibition \\
\hline Colony 3 & Strong Inhibition & Strong Inhibition & Strong Inhibition & Strong Inhibition & Strong Inhibition \\
\hline Colony 4 & No Inhibition & No Inhibition & No Inhibition & No Inhibition & Moderate Inhibition \\
\hline Colony 5 & Moderate Inhibition & Strong Inhibition & Strong Inhibition & No Inhibition & Strong Inhibition \\
\hline
\end{tabular}

Table 4: Antimicrobial activity of isolated colonies.

Isolated colonies in $10^{-3}$ dilution

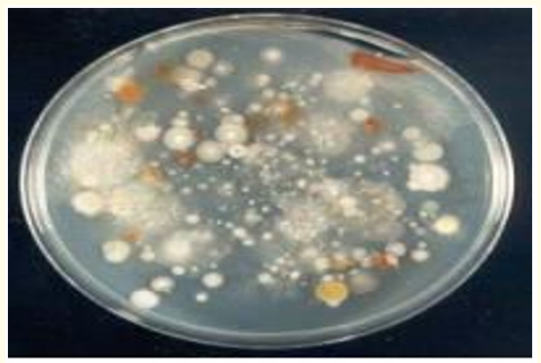

Selected colonies

Figure 5
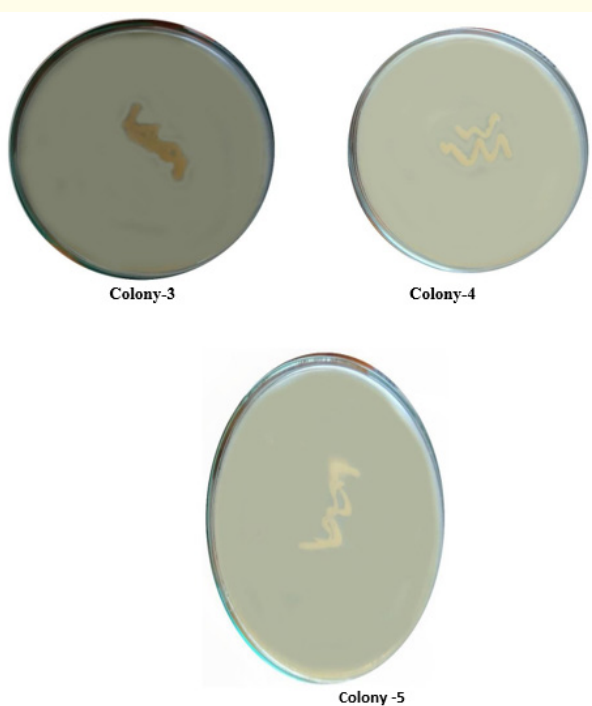

Figure 6
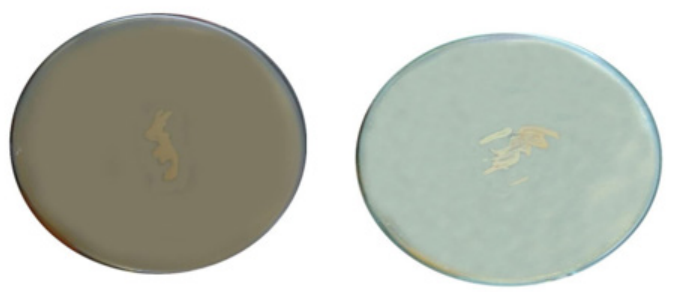
Gram staining
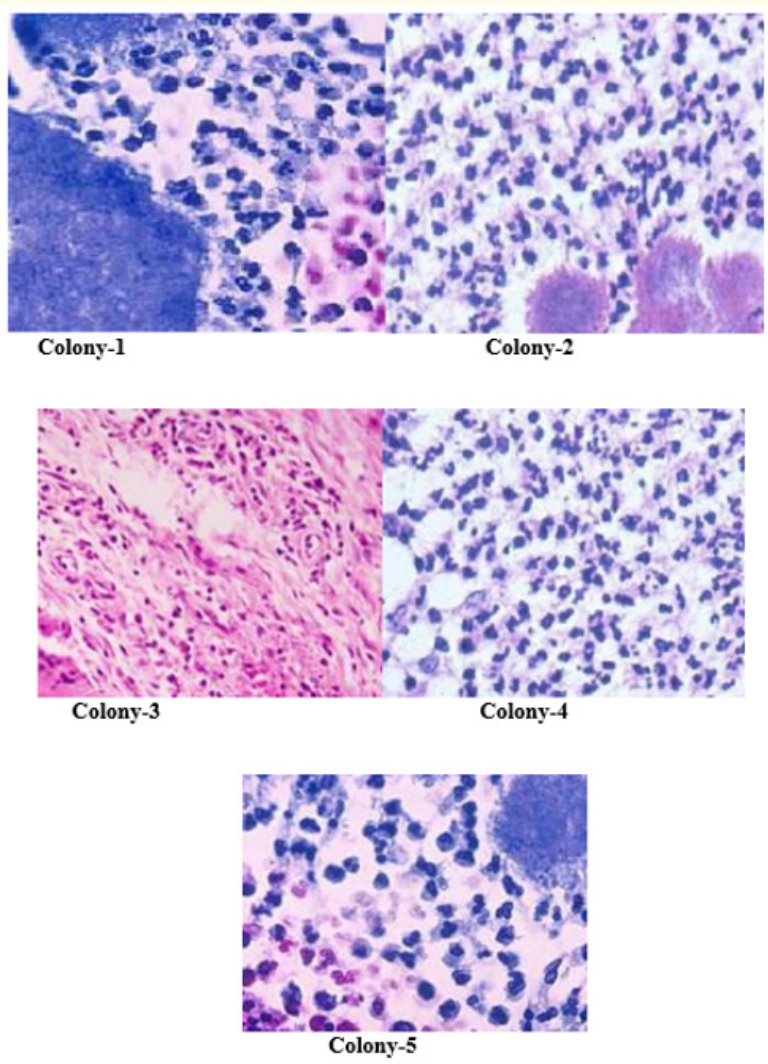

Figure 7

\section{Conclusion}

The present study was an attempt to identify and characterize versatile strains of bacteria and to check their ability for antibiotic production. By performing crowded plate technique, five potential colonies with zone of inhibition were isolated. By performing morphological characterization, the all five colonies were found to be bacteria, of which four colonies were found to be gram positive cocci and one colony gram positive rod. By performing morphological study and biochemical characterization they belong to the Actinobacteria class. The primary screening results conclude that the except one colony all have good antimicrobial activity. Isolated colony 3 was found to be highly potential activity which had inhibition towards gram positive, gram negative, sporulating and fungal activity. This study may contribute in providing information on the antibiotic producing microorganisms in soil. Further characterization, purification, and structural elucidation are recommended to know the novelty, quality and commercial value of these antibiotics [1-25].

\section{Bibliography}

1. Pelczar Michael J., et al. Microbiology. 5th ed., Tata McGrawHill (2010).

2. Kumar A. "Role of Microbes in food and industrial Microbiology". Journal of Food and Industrial Microbiology 2 (2016): 2.

3. Fátima Fonseca., et al. "The Basis for Carbapenem Hydrolysis by Class A $\beta$-Lactamases: A Combined Investigation using Crystallography and Simulations". Journal of the American Chemical Society 134.44 (2012).

4. Foster W and Raoult A. "Early descriptions of antibiosis". Journal of the Royal College of General 24.149 (1974): 889-894.

5. Gillor 0., et al. "Genetically engineered bacteriocins and their potential as the next generation of antimicrobials". Current Pharmaceutical Design 11.8 (2005): 1067-1075.

6. Martin J W. "Manual of Commercial Methods in Clinical Microbiology". Emergency Infection Disease 9.1 (2003): 141-142.

7. Nikaido H. "Multidrug Resistance in Bacteria". Annual Review of Biochemistry 78 (2009): 119-146.

8. Ong S., et al. "Antibiotic use for emergency department patients with upper respiratory infections: prescribing practices, patient expectations, and patient satisfaction". Annals of Emergency Medicine 50.3 (2007): 213-220.

9. Saghee Madhu Raju., et al. "Microbiology and Sterility Assurance in Pharmaceuticals and Medical Devices". 1st ed., Business Horizons (2011).

10. Shinjoh M., et al. "Cloning and nucleotide sequencing of the membrane-bound L-sorbosone-dehydrogenase gene of Acetobacter liquefaciens IFO 12258 and its expression in Gluconobacter oxydans". Applied Environment and Microbiology 61.2 (1995): 413-420.

11. Shinjoh M., et al. "L-sorbose dissimilation in 2-keto-L-gluconic acid- producing mutant UV 10 derivative from Gluconobacter oxydans IFO 3293". Agricultural and Biological Chemistry 54 (1990): 2257-2263.

12. Stroshane RM and Perlman D. "Fermentation of glucose by Acetobacter melanogenus". Biotechnology and Bioengineering 19.4 (1997): 459-465.

13. Underdown BJ and Schiff JM. "Immunoglobulin A: strategic defense initiative at the mucosal surface". Annual Review of Immunology 4.1 (1986): 389-417.

14. Ledesma-Amaro R., et al. "Microbial production of food ingredients". Enzymes and Nutraceuticals (2013): 571-594. 
15. Sengupta S., et al. "The multifaceted roles of antibiotics and antibiotic resistance in nature". Frontiers in Microbiology 4 (2013): 47.

16. Demain AL. "Antibiotics, natural products essential to human health". Medicinal Research Reviews 29.6 (2009): 821-842.

17. Baltz RH. "Marcel Faber Roundtable, is our antibiotic pipeline unproductive because of starvation, constipation or lack of inspiration?". Journal of Industrial Microbiology and Biotechnology 33.7 (2006): 507-513.

18. Molinari G. "Natural products in drug discovery: present status and perspectives". Advances in Experimental Medicine and Biology 655 (2009): 13-27.

19. Makut MD and Owolewa OA. "Antibiotic-producing fungi present in the soil environment of Keffi metropolis, Nasarawa state, Nigeria". Trakia Journal of Sciences 9.2 (2011): 33-39.

20. Hussein AA and AL-Janabi S. "Identification of bacitracin produced by local isolate of Bacillus licheniformis". African Journal of Biotechnology 5.18 (2006): 1600-1601.

21. Waites Michael J., et al. Industrial Microbiology an Introduction, Blackwell (2007).

22. Rafiq A., et al. "Isolation and identification of antibiotic producing microorganisms from soil". International Journal of Pharmaceutical Sciences and Research 9.3 (2018): 1002-1011.

23. Ma K and Kim SD. "Development of techniques for isolating microorganisms". Enliven: Microbes and Microbial Techniques 5.1 (2018): 1-5.

24. Demain Arnold L., et al. "Manual of Industrial Microbiology and Biotechnology". 2nd ed., American Society for Microbiology (1999).

25. Brennan John. "Crowded Plate Techniques in Microbiology". Sciencing (2019).

\section{Assets from publication with us}

- Prompt Acknowledgement after receiving the article

- Thorough Double blinded peer review

- Rapid Publication

- Issue of Publication Certificate

- High visibility of your Published work

Website: www.actascientific.com/

Submit Article: www.actascientific.com/submission.php

Email us: editor@actascientific.com

Contact us: +919182824667 